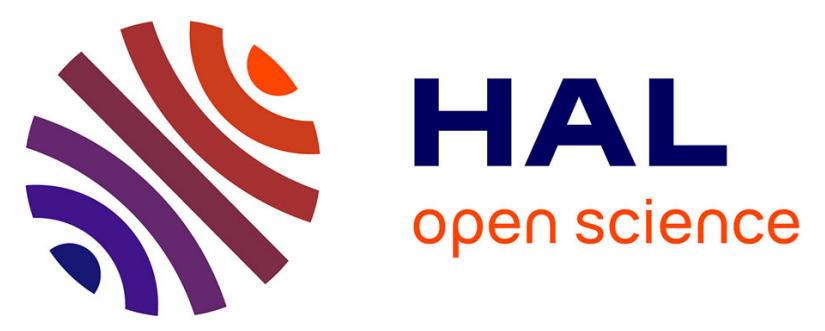

\title{
Complex Polypropionates from a South China Sea Photosynthetic Mollusk: Isolation and Biomimetic Synthesis Highlighting Novel Rearrangements
}

Qihao Wu, Song-Wei Li, Heng Xu, Hong Wang, Pei Hu, Hao Zhang, Cheng Luo, Kai-Xian Chen, Bastien Nay, Yue-Wei Guo, et al.

\section{To cite this version:}

Qihao Wu, Song-Wei Li, Heng Xu, Hong Wang, Pei Hu, et al.. Complex Polypropionates from a South China Sea Photosynthetic Mollusk: Isolation and Biomimetic Synthesis Highlighting Novel Rearrangements. Angewandte Chemie International Edition, 2020, 59, pp.12105-12112. 10.1002/anie.202003643 . hal-02614321

\section{HAL Id: hal-02614321 \\ https://hal.science/hal-02614321}

Submitted on 20 May 2020

HAL is a multi-disciplinary open access archive for the deposit and dissemination of scientific research documents, whether they are published or not. The documents may come from teaching and research institutions in France or abroad, or from public or private research centers.
L'archive ouverte pluridisciplinaire HAL, est destinée au dépôt et à la diffusion de documents scientifiques de niveau recherche, publiés ou non, émanant des établissements d'enseignement et de recherche français ou étrangers, des laboratoires publics ou privés. 


\title{
Complex Polypropionates from a South China Sea Photosynthetic Mollusk: Isolation and Biomimetic Synthesis Highlighting Novel Rearrangements
}

\author{
Qihao Wu, ${ }^{[a, c, \$]}$ Song-Wei Li ${ }^{[a, d, \$]}$ Heng Xu, ${ }^{[a, \S]}$ Hong Wang, ${ }^{[c]}$ Pei Hu, ${ }^{[a]}$ Hao Zhang, ${ }^{[a]}$ Cheng Luo, ${ }^{[a, e]}$ \\ Kai-Xian Chen, ${ }^{[a, e]}$ Bastien Nay, ${ }^{*[b]}$ Yue-Wei Guo*[a,e] and Xu-Wen Li ${ }^{*[a, e]}$
}

\begin{abstract}
Placobranchus ocellatus, regarded as a "solar-powered" sacoglossan mollusk, is well known to produce diverse and complex $\gamma$-pyrone polypropionates. Unexpectedly, in this study, the chemical investigation of $P$. ocellatus from the South China Sea led to the discovery of ocellatusones A-D, a series of racemic non- $\gamma$ pyrone polyketides with novel skeletons, characterized by a bicyclo[3.2.1]octane $(\mathbf{1}, \mathbf{2})$, a bicyclo[3.3.1]nonane (3) or a mesitylene-substituted dimethylfuran-3(2H)-one core (4). Extensive spectroscopic analysis, quantum chemical computation, chemical synthesis, and/or X-ray diffraction analysis were used to determine the structure and absolute configuration of the new compounds, including each enantiomer of racemic compounds 1-4 after chiral HPLC resolution. An important array of new and diversitygenerating rearrangements is proposed to explain the biosynthesis of these unusual compounds based on careful structural analysis and comparison with six known co-occurring $\gamma$-pyrones (5-10). Furthermore, the successful biomimetic synthesis of ocellatusone $A$ (1) from its $\gamma$-pyrone precursor (5) confirmed the biosynthetic relationship of these two compounds and the proposed rearrangement through an unprecedented acid promoted cascade reaction. Besides, an initially untargeted semisynthetic product, polycyclic lactone $\mathbf{1 1}$ with another novel carbocyclic skeleton was proved to be naturally occurring in the mollusk by comparative LCMS/MS analysis, which provides a strategy to fish a vast number of novel trace components in Nature.
\end{abstract}

Marine sacoglossan mollusks are small colorful animals known to harbor defensive or deterrent metabolites, which may have key roles in their protection. ${ }^{1}$ Those mollusks feed on algae and some of them are able to sequester algal chloroplasts by a phenomenon known as kleptoplasty, resulting in photosynthetic capabilities and subsequent $\mathrm{CO}_{2}$ fixation. ${ }^{2}$ Among the defensive metabolites, $y$-pyrone-containing polypropionates constitute a complex and diversified group of natural products found in many slug species, involving

[a] Dr. Q. Wu, S.-W. Li, H. Xu, P. Hu, Dr. H. Zhang, Prof. C. Luo, Prof. K.-X. Chen, Prof. Y.-W. Guo, Prof. X.-W. Li

State Key Laboratory of Drug Research, Shanghai Institute of Materia Medica, Chinese Academy of Sciences

555 Zu Chong Zhi Road, Zhangjiang Hi-Tech Park, Shanghai 201203, China

Email: xwli@simm.ac.cn

[b] B. Nay

$$
\text { ywguo@simm.ac.cn }
$$

Laboratoire de Synthèse Organique, Ecole Polytechnique, ENSTA, CNRS, Institut Polytechnique de Paris, 91128 Palaiseau Cedex, France

Email: bastien.nay@polytechnique.edu

[c] Dr. Q. Wu, Prof. H. Wang

College of Pharmaceutical Science and Collaborative Innovation Center of Yangtze River Delta Region Green Pharmaceuticals, Zhejiang University of Technology, Hangzhou 310014, China

[d] S.-W. Li

Nanjing University of Chinese Medicine, 138 Xianlin Road, Nanjing 210023,

[e] Prof. C. Luo, Prof. K.-X. Chen, Prof. Y.-W. Guo, Prof. X.-W. Li Open Studio for Druggability Research of Marine Natural Products, Pilot National Laboratory for Marine Science and Technology (Qingdao)

1 Wenhai Road, Aoshanwei, Jimo, Qingdao, 266237, China

[§] The authors contribute equally to this work. photoinduced cyclizations during their biosynthesis. ${ }^{3}$ They are found in the mantle, the cerata (dorsal appendages that detach upon predator's attack) or the mucus of the animal, and would be toxic against predators. ${ }^{3 c, 4}$ However, other hypotheses have been emitted concerning their ecological role, owing to the ability of these polyunsaturated compounds to absorb UV light and to react photochemically. They could thus behave as a natural sunscreen against harmful sun radiations and have protective effects against oxidative damages. ${ }^{5}$

In vivo ${ }^{14} \mathrm{C}$-feeding experiments in some sacoglossan species suggested that the $\gamma$-pyrones would be biosynthesized by the mollusks themselves and then cyclized by late nonenzymatic light-triggered reactions, rather than being acquired from their dietary sources. ${ }^{2 a, 3 c, 4}$ Until recently, there had been no direct study to prove this assertion, i.e. through experiments on animal cells or genes. A symbiotic origin was still possible, as reported for cone snail pyrone polypropionates, ${ }^{6}$ while a fungal origin for sacoglossan compounds had been ruled out. ${ }^{7}$ However, a recent study by Schmidt and coworkers excluded a bacterial origin and demonstrated that the gene ECPKS1 found in the animal genome but not in the sequestered algal chloroplast- was responsible for the biosynthesis of pyrone polyenes, after heterologous expression in yeast. ${ }^{8}$ The gene is present in Elysia chlorotica, while homologues were found in Placobranchus ocellatus.

- Known skeletons

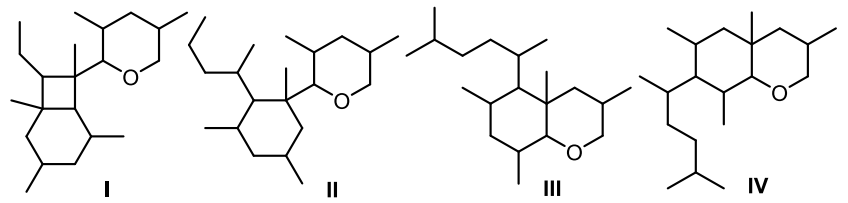

- New skeletons described in this work

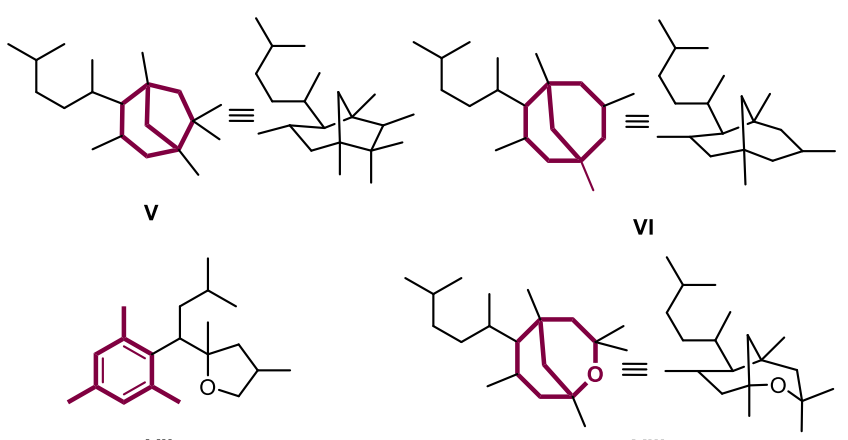

VII

VIII

Figure 1. Structure of $y$-pyrones polypropionates and new skeletons reported in this work.

Structurally, the sacoglossan polypropionates show a characteristic $\gamma$-pyrone connected to a variety of complex cyclic systems and/or unsaturated side chains (skeletons I-IV, Figure 1). ${ }^{3 a, 9}$ The beautiful molecular architectures of these metabolites and their amazing photobiosynthetic routes have attracted a lot of attention from chemists seeking to perform their total synthesis using biomimetic strategies, ${ }^{10}$ in parallel to 
ecological and biological investigations. ${ }^{2,3}$ It is worth mentioning that some of these complex molecules were isolated from $P$. ocellatus by interesting photosynthetic rearrangements. ${ }^{2 \mathrm{a}, 11}$

As part of our endeavor to explore the bioactive secondary metabolites from Chinese marine mollusks, ${ }^{9 b, 12}$ especially those bioactive marine propionates, ${ }^{9 b, 12 d-f}$ the marine sacoglossan $P$. ocellatus (phylum Mollusca, class Gastropoda, subclass Opisthobranchia, order Sacoglossa), collected from the shallow water of Ximao Island, Hainan Province, China, was chemically investigated with the aim to discover new chemical markers with novel diversity and complexity. In that context, we now describe the discovery of four novel types of complex polypropionates, providing three unprecedented carbocyclic skeletons (V-VII, Figure 1), named ocellatusones A-D (1-4), which were all found in a racemic form (Figure 2). Exceptionally, one of them incorporates a mesityl substituent, which is obviously the product of a complex biosynthetic mechanism. In addition, six known (5-10) $y$-pyrone polypropionates were isolated. The biosynthetic origin of the

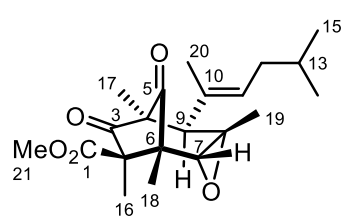

$(+)-1: 2 R, 4 R, 6 S, 7 R, 8 S, 9 R$ (as drawn) $(-)-1: 2 S, 4 S, 6 R, 7 S, 8 R, 9 S$

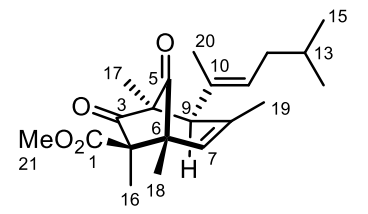

$(+)-2: 2 R, 4 R, 6 R, 9 S$ (as drawn) $(-)-2: 2 S, 4 S, 6 S, 9 R$

new compounds, involving unique rearrangements, will be discussed, with the strong support of complex biomimetic Lewis acid-catalyzed, semisynthetic transformations. Furthermore, an initially untargeted semisynthetic product, polycyclic lactone $\mathbf{1 1}$ with another new carbocyclic skeleton (VIII), was used as a reference to explore its presence in the crude natural extract by LC-MS/MS, confirming its occurrence in the mollusk.

The external tissues extract of $P$. ocellatus gave pure compounds 1-10. Known compounds 5-10 were readily identified as tridachiahydropyrone (5), ${ }^{10 \mathrm{c}, 13}$ phototridachiahydropyrone (6), ${ }^{14}$ tridachiahydropyrones B (7) and C (8), ${ }^{10 d, 11 a, 15}$ ocellapyrone B (9), ${ }^{10 a, 11 b}$ and 14methylelysiapyrone $A(\mathbf{1 0}),{ }^{10 a}$ respectively, by comparing their NMR data with those reported in the literature. Incidentally, 14methylelysiapyrone A (10) has previously only been reported as a synthetic derivative of ocellapyrone $B(9),{ }^{10 a}$ and is herein described as a natural product for the first time.

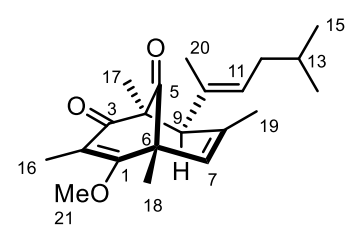

(+)-3: 4R,6S,9R

(-)-3: 4S,6R,9S (as drawn)

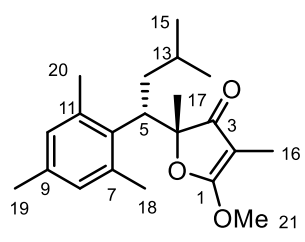

(+)-4: 4R,5S (as drawn) $(-)-4: 4 S, 5 R$<smiles></smiles>

$(+)-5: 4 S, 9 R$ (as drawn) $(-)-5: 4 R, 9 S$

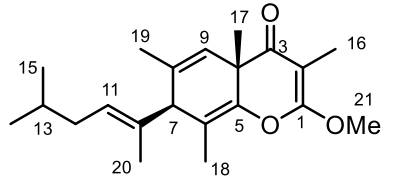

$(+)-6: 4 S, 7 S$ (as drawn) $(-)-6: 4 R, 7 R$<smiles>COOC12C(=O)C(C)=C(OC)C(=O)C1(C(C)=CCC(C)C)C(C)C=C2C</smiles>

(+)-7: $4 R, 5 R, 8 S, 9 S$ (as drawn) $(-)-7: 4 S, 5 S, 8 R, 9 R$

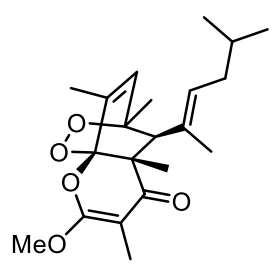

$(+)-8: 4 R, 5 R, 8 S, 9 S$ (as drawn) $(-)-8: 4 S, 5 S, 8 R, 9 R$

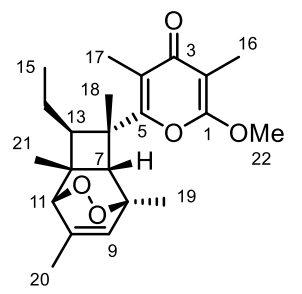

(+)-9: 6R,7S,8R,11S,12S,13S

(-)-9: $6 S, 7 R, 8 S, 11 R, 12 R, 13 R$ (as drawn)

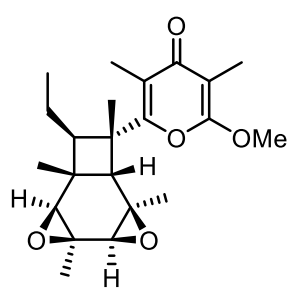

(+)-10: 6R,7S,8S,9S,10R,11R,12S,13S (-)-10: $6 S, 7 R, 8 R, 9 R, 10 S, 11 S, 12 R, 13 R$ (as drawn)

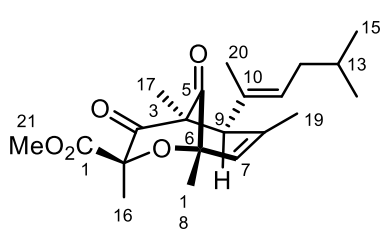

(+)-11: $2 R, 4 R, 6 S, 9 S$ (as drawn) $(-)-11: 2 S, 4 S, 6 R, 9 R$

Figure 2. Chemical structures of compounds 1-11.

Among new compounds ocellatusone A (1) was isolated as a colorless oil. The molecular formula of $\mathbf{1}$ was determined to be $\mathrm{C}_{21} \mathrm{H}_{30} \mathrm{O}_{5}$ by HREIMS ( $\mathrm{m} / \mathrm{z} 362.2097$ [M] $^{+}$, calcd. 362.2088), indicating seven degrees of unsaturation. The ${ }^{13} \mathrm{C}$ NMR and HSQC spectra disclosed 21 carbon signals, including eight methyls, one $\mathrm{sp}^{3}$ methylene, three $\mathrm{sp}^{3}$ methines, four $\mathrm{sp}^{3}$ quaternary carbons, one $\mathrm{sp}^{2}$ methine, and four $\mathrm{sp}^{2}$ quaternary carbons. The diagnostic ${ }^{1} \mathrm{H}$ and ${ }^{13} \mathrm{C}$ NMR resonances, as well as coupling constants of the connected protons [Supporting Information (SI), Table S1 and S2], indicated the presence of one trisubstituted double bond $\left(\delta_{\mathrm{H}} 5.42, \mathrm{t}, J=7.5 \mathrm{~Hz}, \delta_{\mathrm{C}} 134.3\right.$, $\mathrm{CH} ; \delta_{\mathrm{C}} 131.6, \mathrm{qC}$ ), three carbonyls (two ketone carbonyls at $\delta_{\mathrm{C}}$ $208.9,213.9$ and one ester carbonyl at $\left.\delta_{C} 170.2\right)$. The above functionalities account for four of the seven degrees of unsaturation, suggesting the presence of a tricyclic system in $\mathbf{1}$.

Analysis of the ${ }^{1} \mathrm{H}-{ }^{1} \mathrm{H}$ COSY spectrum of compound $\mathbf{1}$ revealed an isoamyl structural fragment (part $\mathbf{I}$ ) as shown in Figure 3 by the clear correlations of $\mathrm{H}_{3}-14\left(\delta_{\mathrm{H}} 0.90\right) / \mathrm{H}-13\left(\delta_{\mathrm{H}}\right.$ 1.66), $\mathrm{H}_{3}-15\left(\delta_{\mathrm{H}} 0.92\right) / \mathrm{H}-13$, and $\mathrm{H}-13 / \mathrm{H}_{2}-12\left(\delta_{\mathrm{H}} 1.94\right) / \mathrm{H}-11\left(\delta_{\mathrm{H}}\right.$
5.42). Furthermore, detailed interpretation of the well resolved HMBC correlations (Figure 3$)$ from $\mathrm{H}_{3}-16\left(\delta_{\mathrm{H}} 1.73, \mathrm{~s}, \delta_{\mathrm{C}} 14.1\right.$, $\left.\mathrm{CH}_{3}\right)$ to C-2 $\left(\delta_{\mathrm{C}} 54.4\right) / \mathrm{C}-6\left(\delta_{\mathrm{C}} 66.0, \mathrm{qC}\right) / \mathrm{C}-3\left(\delta_{\mathrm{C}} 208.9, \mathrm{qC}\right)$, from $\mathrm{H}_{3}-17\left(\delta_{\mathrm{H}} 1.04, \mathrm{~s}, \delta_{\mathrm{C}} 15.2, \mathrm{CH}_{3}\right)$ to $\mathrm{C}-4\left(\delta_{\mathrm{C}} 55.0\right) / \mathrm{C}-9\left(\delta_{\mathrm{C}}\right.$ 69.0, CH)/C-5 ( $\left.\delta_{\mathrm{C}} 213.9, \mathrm{qC}\right) / \mathrm{C}-3$, from $\mathrm{H}_{3}-18\left(\delta_{\mathrm{H}} 1.24, \mathrm{~s}, \delta_{\mathrm{C}}\right.$ $\left.13.1, \mathrm{CH}_{3}\right)$ to $\mathrm{C}-6\left(\delta_{\mathrm{C}} 66.0\right) / \mathrm{C}-2 / \mathrm{C}-7\left(\delta_{\mathrm{C}} 70.8, \mathrm{CH}\right) / \mathrm{C}-5$, from $\mathrm{H}_{3}-$ $19\left(\delta_{\mathrm{H}} 1.14, \mathrm{~s}, \delta_{\mathrm{C}} 20.5, \mathrm{CH}_{3}\right)$ to $\mathrm{C}-8\left(\delta_{\mathrm{C}} 59.2\right) / \mathrm{C}-9 / \mathrm{C}-7$, leading to the construction of a bicyclo[3.2.1]octane skeleton with four methyls (Me-16, Me-17, Me-18, and Me-19) located at C-2, C-4, C-6 and C-8, respectively. The remaining unassigned oxygen atom and typical up-fielded chemical shifts of two oxygenated carbons (C-7 and $\mathrm{C}-8)$, bearing in mind one remaining degree of unsaturation, suggested the presence of a trisubstituted epoxide group at C-7 and C-8, forming a novel oxatricyclo[4.2.1.0 $0^{2,4}$ ]nonane skeleton (part II) of 1 . The connection at C-9 position of the two moieties I and II was deduced by the HMBC correlations from $\mathrm{H}-11$ to $\mathrm{C}-9 / \mathrm{C}-10\left(\delta_{\mathrm{C}}\right.$ $131.6, \mathrm{qC}) / \mathrm{C}-20\left(\delta_{\mathrm{C}} 14.5, \mathrm{CH}_{3}\right)$, and $\mathrm{H}_{3}-20\left(\delta_{\mathrm{H}} 1.54, \mathrm{~s}\right)$ to $\mathrm{C}-$ $10 / C-9 / C-11$, respectively. Finally, the methyl ester group $\left(\delta_{\mathrm{H}}\right.$ 
2.58, s, $\left.\delta_{\mathrm{C}} 52.6, \mathrm{CH}_{3}, \delta_{\mathrm{C}} 170, \mathrm{qC}\right)$ was confirmed to attach at C2 by the clear HMBC correlation from $\mathrm{H}_{3}-16$ to $\mathrm{C}-1$. Based on these observations, the planar structure of $\mathbf{1}$ was established as shown in Figure 3.
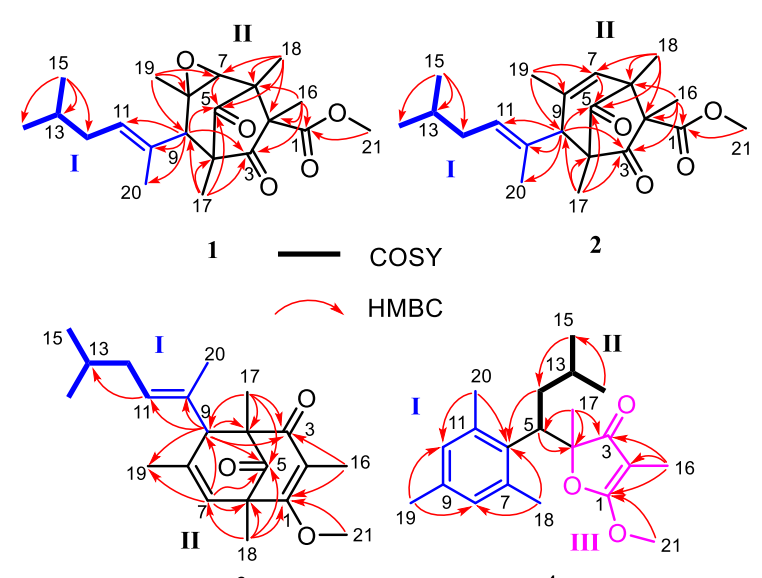

3

4

Figure 3. ${ }^{1} \mathrm{H}-{ }^{1} \mathrm{H}$ COSY and key HMBC correlations of compounds 1-4.

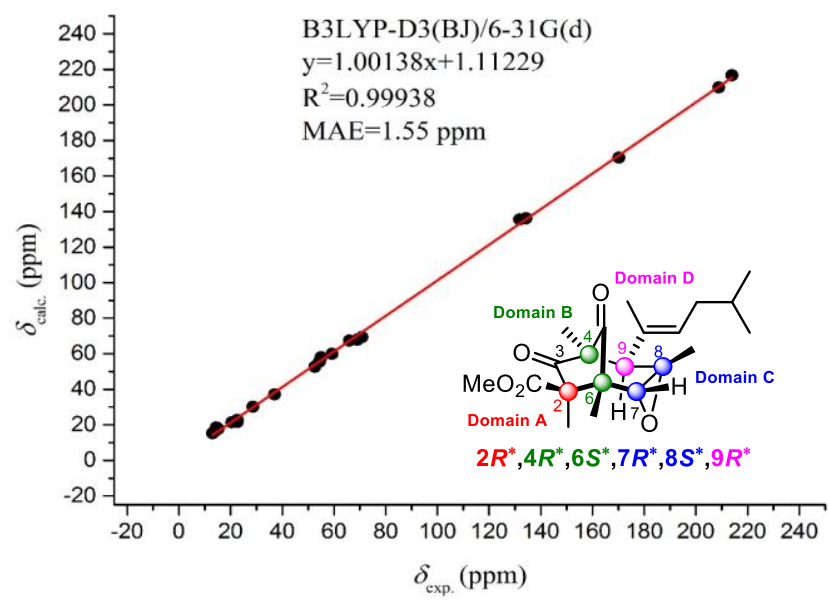

Figure 4. Regression analysis of experimental versus calculated ${ }^{13} \mathrm{C}$ NMR chemical shifts at the B3LYP-D3(BJ)/6-31G(d) level using GIAO method of 1f; the linear fitting is shown as a red line (diagonal).

The determination of the relative configuration of 1 was a challenging task since its six continuous chiral carbons C-2, C-6, C-7, C-8, C-9, and C-4 could only be partially characterized by NOESY spectra. NOESY correlations of $\mathrm{H}-7 / \mathrm{H}_{3}-18, \mathrm{H}-7 / \mathrm{H}_{3}-19$, $\mathrm{H}-9 / \mathrm{H}_{3}-17, \mathrm{H}-9 / \mathrm{H}_{3}-19, \mathrm{H}_{3}-16 / \mathrm{H}_{3}-18$ were not informative on the relative configuration of $\mathbf{1}$ (Figure S31, Table S3). Furthermore, the oily nature of 1 prohibited the growth of a suitable crystal. Thus, to solve this problem, we relied on ab initio NMR calculations, regarded as one of the most powerful and reliable methods to characterize structurally complex natural products, ${ }^{16}$ by using the time dependent density functional theory (TDDFT) gauge independent atomic orbital (GIAO) method. The chiral centers of 1 were distributed in four domains A-D (Figure 4), defining eight possible relative configurations in compounds 1a-1h (Figure S32). The experimental NMR data of $\mathbf{1}$ were compared with the calculated NMR chemical shifts of $\mathbf{1 a}-\mathbf{1 h}$ (Table S4) using the mean absolute error (MAE) values and correlation coefficient $\left(R^{2}\right)$ analysis. The calculated NMR data for $1 \mathrm{f}$ showed the best overall agreement with the experimental data (Figure 4) with the smallest MAE value (1a: 1.96, 1b: 2.08 , 1c: $2.10,1 \mathrm{~d}: 1.98, \mathbf{1 e}: 1.94, \mathbf{1 f}: 1.55, \mathbf{1 g}: 1.89$, and 1h: 2.15; Table S5, Figures S35-S42) and the highest ${ }^{13} \mathrm{C}$ chemical shift correlation coefficient value (1a: $0.99864,1 \mathbf{b}: 0.99847,1 \mathrm{c}$ : 0.99843, 1d: 0.99877, 1e: 0.99884, 1f: 0.99938, 1g: 0.99878, and 1h: 0.99890; Table S5, Figures S35-S42). The relative configuration of compound $\mathbf{1}$ was finally determined as
$2 R^{*}, 4 R^{*}, 6 S^{*}, 7 R^{*}, 8 S^{*}, 9 R^{*} \quad$ (Figure 4). Importantly, the biosynthetic hypotheses discussed below supports this relative stereochemistry.

The planar structures of the other newly isolated ocellatusones B-D (2-4) were elucidated by the same 1D and 2D NMR techniques (Figure 3, Tables 1 and 2), and mass spectrometry (see SI for the detailed analysis) as those of 1 . As a 7,8-de-epoxy derivative of 1 , ocellatusone $B(2)$ was determined to have the same relative configuration at C-2, C-4, $\mathrm{C}-6$, and $\mathrm{C}-9$ as 1 . The relative configuration of 3 was determined as $\left(4 S^{\star}, 6 R^{\star}, 9 R^{\star}\right)$ by using the same ab initio NMR calculations as that of 1 (Figure S46 and S47, Table S6).

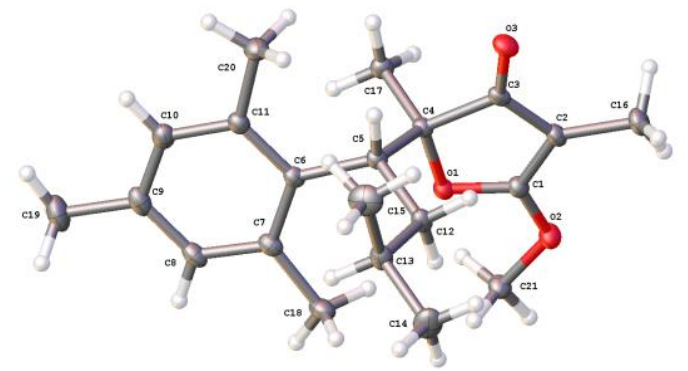

Figure 5. Perspective ORTEP drawing of X-ray structure of 4 (ellipsoids shown at the $50 \%$ probability level).

The structure of $\mathbf{4}$ was fortunately confirmed by X-ray crystallography using $\mathrm{Ga} \mathrm{Ka}$ radiation $(\lambda=1.34139 \AA)$, after recrystallization from dichloromethane (Figure 5, CCDC 1921726). The crystals of 4 had a P-1 space group, indicating its racemic nature, ${ }^{10 \mathrm{~d}, 17}$ as confirmed later by chiral preparative HPLC. Analysis of the X-ray data not only confirmed the structure of $\mathbf{4}$ but also unambiguously determined its relative configurations as $4 R^{\star}, 5 S^{\star}$. Noteworthily, the occurrence of a mesitylene ring in a natural product is exceptional. As far as we know, this motif has been described once by Hertweck, Trauner and co-workers as a fragment released during the biosynthesis of orinocin, through a mechanism formally described as a "polyene splicing". ${ }^{18}$

The lack of optical activity for new compounds 1-4 was indicative of their possible racemic nature. Subsequently, they were successfully separated via chiral HPLC to yield four pairs of optically pure enantiomers. Each pair was equimolar, confirming the racemic character of the isolated compounds. Furthermore, the absolute configuration of all enantiomers was determined by TDDFT-ECD calculations ${ }^{19}$ (see demonstration in the SI). Similarly, the known compounds 5, 6, the rotamer mixture of $\mathbf{7}$ and $\mathbf{8}, \mathbf{9}$, and $\mathbf{1 0}$ were identified as racemic compounds due to the lack of optical activity, and were all successfully separated by chiral HPLC to afford five equimolar pairs of optically pure enantiomers. Their absolute configurations were also determined for the first time by TDDFT-ECD calculations (see demonstration in the SI).

The polypropionate nature of the novel compounds ocellatusones A-D (1-4) was deduced from their co-occurrence with the well documented tridachiahydropyrone (5), phototridachiahydropyrone (6), tridachiahydropyrones B (7) and C (8). All are biosynthetically related, sharing common structural features such as an isoamyl moiety and the presence of 1,3-positionned methyl substituents. In addition, the stereochemistry of precursor $\mathbf{5}$ (Scheme 1) furnished an important indication to predict the relative stereochemistry of compounds 1-3 during the structure determination work. However, compounds 1-4 do not have the characteristic $\gamma$ pyrone fragment of the more classical series, showing deep reorganization of the $\gamma$-pyrone polypropionate skeleton. Furthermore, their racemic nature was indicative of nonenzymatic biosynthetic processes, possibly under the control of light and acid catalysis. Bearing in mind that the animal was exposed to UV sunlight radiation at the depth of 0-2 meters in the sea where they were collected, we propose a photobiosynthetic pathway from possible triene precursor 12 to 
compounds 1-4. Under photochemical conditions, 12 could undergo an $E$-to- $Z$ isomerization to afford either 12 a (route $A$ ) or 12b (route B). Intermediate 12a would further react through a $6 \pi$ conrotatory electrocyclization under light activation to generate tridachiahydropyrone $\mathbf{5}$, which would then undergo a photocatalyzed [1,3]-sigmatropic shift giving phototridachiahydropyrone $\mathbf{6}$, as previously demonstrated by Moses and co-workers through biomimetic synthesis. ${ }^{3 b, 10 c-d}$ From tridachiahydropyrone $\mathbf{5}$, a divergent route would afford compounds 1-3. Under acidic activation, the $\gamma$-pyrone ring of 5 would be opened into $\beta$-ketoester 13 , substrate of a Claisen condensation to form compound $\mathbf{3}$. Alternatively, intermediate $\mathbf{5}$ could be either epoxidized or photooxygenated towards endoperoxide $\mathbf{7}$ and monoepoxide $\mathbf{1 4}$. The former (7) is known to readily isomerize into diepoxide $7 a{ }^{20}$ Acid-promoted opening of acetalic epoxides $\mathbf{7 a}$ (through hydration) and 14, and formation of carbocations $7 \mathrm{c}$ and $14 a$, respectively, could lead to stereocontrolled transannular cyclizations. This sequence could explain the relative configuration observed at the $\alpha$ position of the esters in natural products 1 and 2 , respectively. Although compound $\mathbf{1}$ could also result from the epoxidation of compound 2, we will next discuss that direct conversion of 7 into 1 could be successfully performed through one-step biomimetic semisynthesis, proving that this route could likely occur in nature.<smiles>COc1oc(/C=C(\C)C=C(C)C=CCC(C)C)c(C)c(=O)c1C</smiles>

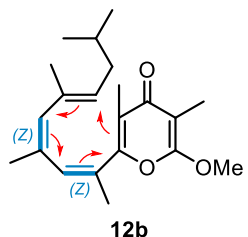

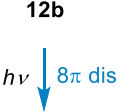<smiles>COC1=C(C)C(=O)C23OC(C)=C(C)CC2(CC(C)C)C(C)=CC(C)=CC3=C1C</smiles>

15 $h v \downarrow 6 \pi$ con

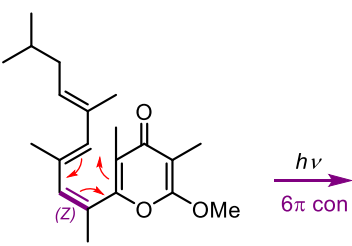

$12 \mathrm{a}$

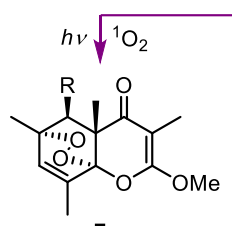

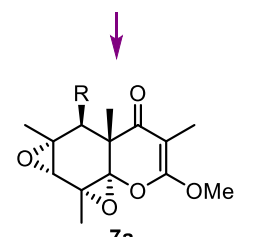

$7 a$

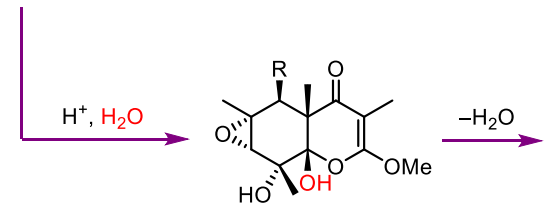

$7 b$

14
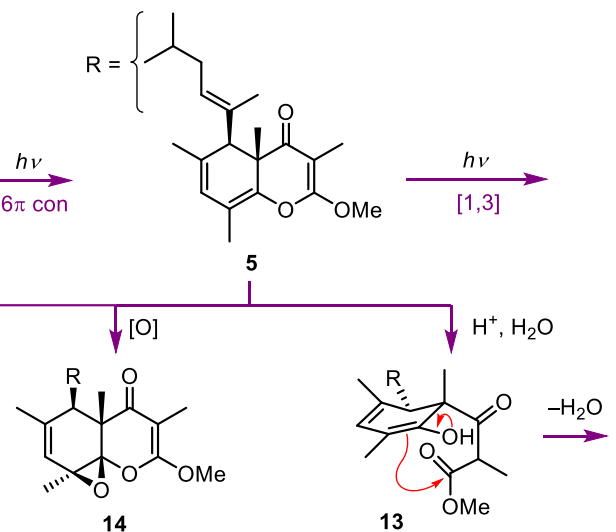

13
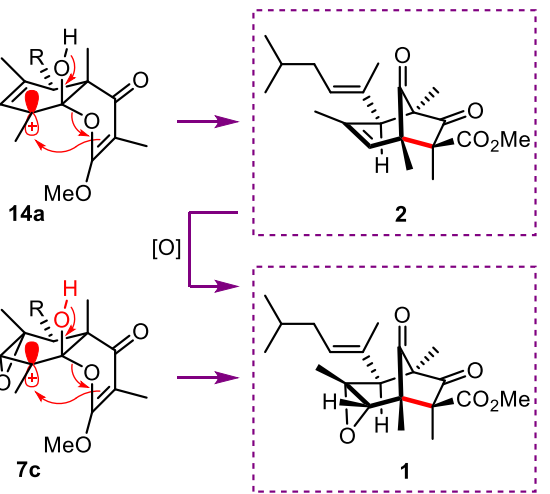

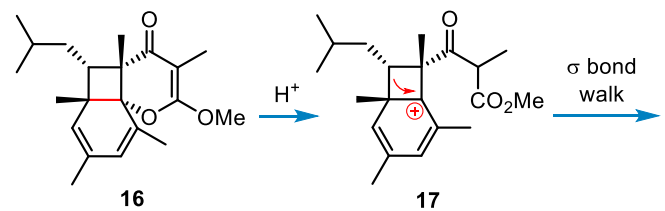

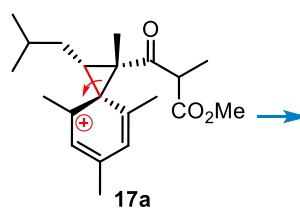

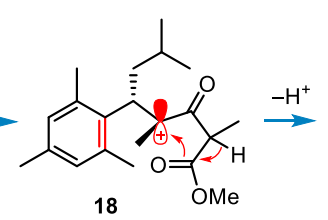

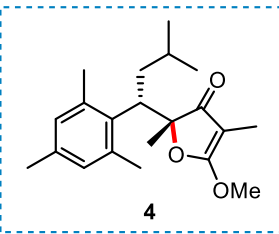

Scheme 1 Proposed photobiosynthetic pathway towards isolated novel polyketides 1-4 (The hypothesis for $\mathbf{6}$ was previously stated and confirmed by Truner's biomimetic synthesis, whereas that for 1 was confirmed by this work).

Concerning compound 4 , photochemical $8 \pi$ disrotatory then $6 \pi$ conrotatory electrocyclizations of $\mathbf{1 2 b}$ (route B) would lead to highly strained compound $\mathbf{1 6}$. This intermediate would evolve to phenonium carbocation 17. In order to form the mesitylene substituent, we hypothesized a $\sigma$-bond walk through WagnerMeerwein 1,2-migration resulting in cyclobutane ring contraction into cyclopropane $17 \mathrm{a}$, followed by cyclopropane bond cleavage leading to the aromatization of the phenonium into the mesityl ring (18). Finally, the resulting cation ${ }^{21}$ would be neutralized by intramolecular cyclization to form the dimethylfuran-3(2H)-one nucleus of ocellatusone D (4) (Scheme 1).

Following the previous hypothesis, the biosynthetic conversion of $\mathbf{5}$ into bridged compound $\mathbf{1}$ was then challenged by biomimetic synthesis and acid-promoted rearrangements (Table 1). Thus, compound $\mathbf{5}$ was submitted to photosensitized oxygenation by singlet oxygen, generated from $\mathrm{O}_{2}$ under $250 \mathrm{~W}$ long arc mercury lamp irradiation in the presence of methylene blue, to afford 7 with $90 \%$ yield. ${ }^{10 a}$ In addition, to test the biomimetic formation of $\mathbf{7}$, precursor 5 could be photooxygenated under similar condition in the presence of the natural photosensitizer $13^{2}$-hydroxy-chlorophyll, ${ }^{22}$ a metalcontaining chlorophyll concomitantly isolated during this work (Figure S51). Gratifyingly, this reaction proceeded successfully, leading to 7 in $80 \%$. We then attempted to form product 1 in the presence of various Lewis acid catalysts (Table 1). Inspired by Trauner's ruthenium-catalyzed isomerization of ocellapyrone $B$ into 14-methylelysiapyrone $\mathrm{A},{ }^{10 a}$ we first used $\mathrm{RuCl}_{2}\left(\mathrm{PPh}_{3}\right)_{3}$ as a catalyst to generate diepoxide 7a. However, we were astounded to obtain directly compound 1 with nearly $30 \%$ yield, which could not be improved by changing the amount of catalyst, the temperature, or the reaction time (Table 1). Then we screened other acids, such as $\mathrm{FeCl}_{2}, \mathrm{ZnCl}_{2}, \mathrm{PdCl}_{2}$ (dppf), CoTPP (cobalt tetraphenylporphyrin), and trifluoroacetic acid 
(TFA). ${ }^{20}$ Although the expected product 1 was formed in all cases, $\mathrm{ZnCl}_{2}$ proved to be the best catalyst, with a yield of $53 \%$ after isolation, or $88 \%$ based on the recovered starting material (b.r.s.m). In addition, the treatment of 7 in silica gel during $48 \mathrm{~h}$ at room temperature led to no reaction, indicating that compound 1 cannot be an artifact of the isolation process.

Table 3. Biomimetic synthesis of novel compound $\mathbf{1}$ from compound $\mathbf{5}$.

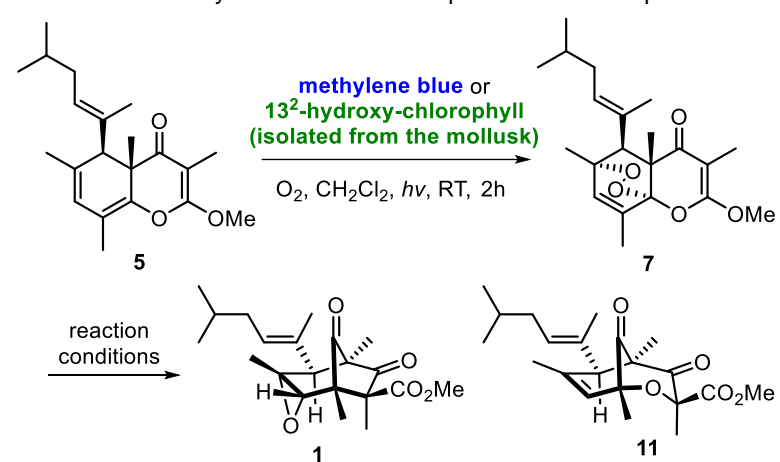

\begin{tabular}{cll}
\hline Entry & Reaction conditions $^{a}$ & $\begin{array}{l}\text { Products } \\
\text { and yields [\%] }\end{array}$ \\
\hline 1 & {$\left[\mathrm{RuCl}_{2}\left(\mathrm{PPh}_{3}\right)_{3}\right], 0^{\circ} \mathrm{C}-\mathrm{RT}, 48 \mathrm{~h}$} & $\mathbf{1}\left(27^{b}, 45^{c}\right)$ \\
2 & {$\left[\mathrm{RuCl}_{2}-\left(\mathrm{PPh}_{3}\right)_{3}\right], 0-40^{\circ} \mathrm{C}, 24 \mathrm{~h}$} & $\mathbf{1}\left(31^{b}, 42^{c}\right)$ \\
3 & $\mathrm{PdCl}_{2}(\mathrm{dppf}), 0^{\circ} \mathrm{C}-\mathrm{RT}, 24 \mathrm{~h}$ & $\mathbf{1}\left(26^{b}, 52^{c}\right)$ \\
4 & $\mathrm{ZnCl}_{2}, 0^{\circ} \mathrm{C}-\mathrm{RT}, 24 \mathrm{~h}$ & $\mathbf{1}\left(53^{b}, 88^{c}\right)$ \\
5 & $\mathrm{FeCl}_{2}, 0^{\circ} \mathrm{C}-\mathrm{RT}, 4 \mathrm{~h}$ & $\mathbf{1}\left(38^{b}\right), \mathbf{1 1}\left(27^{b}\right)$ \\
6 & $\mathrm{CoTPP}, \mathrm{CH}_{2} \mathrm{Cl}_{2}, 0^{\circ} \mathrm{C}-\mathrm{RT}, 4 \mathrm{~h}$ & $\mathbf{1}\left(43^{b}\right)$ \\
7 & $\mathrm{TFA}, 0^{\circ} \mathrm{C}-\mathrm{RT}, 24 \mathrm{~h}$ & $\mathbf{1}\left(17^{b}\right)$ \\
8 & Silica, RT, $48 \mathrm{~h}$ & No reaction
\end{tabular}

${ }^{a}$ The equivalent of each acid and Silica was 1.5 and 20 , respectively. All reactions run in $\mathrm{CH}_{2} \mathrm{Cl}_{2}$ unless otherwise noted. ${ }^{b}$ Isolated yield. ${ }^{c}$ B.r.s.m yield.

Last but not least, the reaction of 7 in the presence of $\mathrm{FeCl}_{2}$ afforded novel cycloether product 11 beside 1, after only 4 hours. This reaction was also observed in a one-pot synthesis starting from 5 (directly adding $\mathrm{FeCl}_{2}$ into the photosensitized oxygenation mixture), with similar reaction time and yields for both products. More strikingly, this compound lacks the expected epoxide on the three-carbon bridge, indicating an alternative reactivity of endoperoxide 7 . This transformation formally resulted in an oxygen transfer from the endoperoxide to the $\alpha$ position of the $\beta$-keto ketene acetal. The combination of $\mathrm{Fe}(\mathrm{II})$ and peroxides, during Fenton-type reactions, have previously been reported to oxidize the $\alpha$ position of 1,3dicarbonyl compounds. ${ }^{23}$ We supposed that a Fenton reaction in the presence of $\mathrm{FeCl}_{2}$ would first cleave the endoperoxide into oxy radical 12 which would result in the release of oxidant $\mathrm{Fe}(\mathrm{IV})=\mathrm{O}$ species and epoxide 12a (Scheme 2). Hydrolysis of the epoxide and oxidative cyclization of $12 \mathrm{~b}$ into $12 \mathrm{c}$ would finally release cycloether $\mathbf{1 1}$ in a stereospecific manner.

With compound $\mathbf{1 1}$ in hand, we decided to use it as a reference compound to explore its presence in the crude animal extract by a LC-MS/MS method (Figure S58), reasoning that the rearrangement of 7 into 11 could also occur in vivo. Thus, at the same retention time as the reference product, we found a compound with the same $\mathrm{m} / \mathrm{z}$ as $11\left(363.2,[\mathrm{M}+\mathrm{H}]^{+}\right)$, sharing seemingly identical MS/MS spectrum (cosine similarity score = $0.81)^{24}$ (Figure S67). Therefore, although this compound was not isolated from the crude extract, this new finding strongly supports its presence in the mollusk. It also shows that a supposedly biomimetic oxidative transformation can furnish a valuable sample for compound fishing in a natural extract. ${ }^{25}$

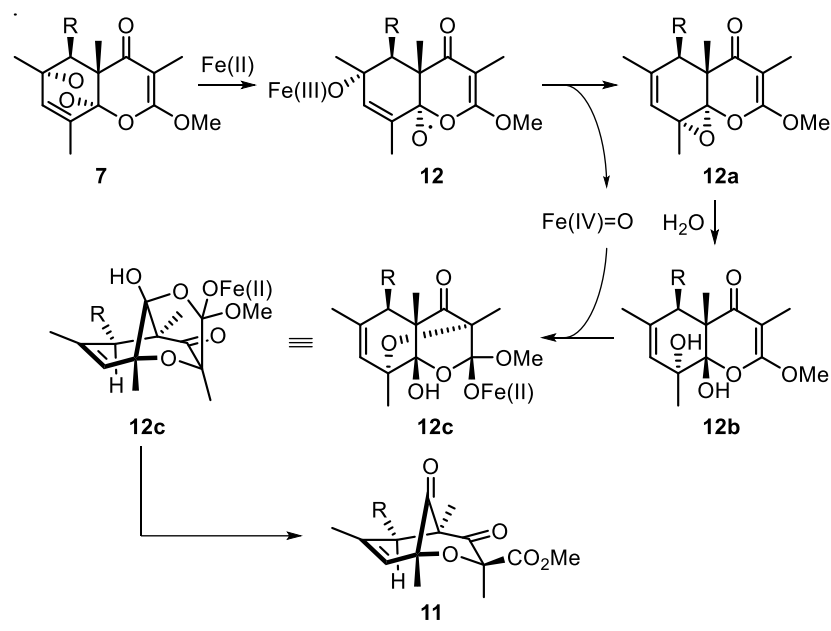

Scheme 2. Proposed Fe(II)-catalyzed reaction towards novel polyketide 11.

In summary, the first chemical investigation of the South China Sea sacoglossan $P$. ocellatus has resulted in the isolation and identification of four racemic polyketides (1-4) with unprecedented carbon skeletons, along with six known related $\gamma$-pyrone polypropionates (5-10). Ocellatusones A-C (1-3) are the first example of bridged polypropionates with uncommon oxatricyclo[4.2.1.0 $0^{2,4}$ ]nonane (1), bicyclo[3.2.1]octane (2), and bicyclo[3.3.1]nonane (3) skeletons, respectively, whereas ocellatusone D (4) represents a unique dimethylfuran-3(2H)one nucleus connected with a mesitylene moiety. A suite of computationally assisted calculation methods, chemical synthesis, and X-ray diffraction analysis were applied to unequivocally establish the relative configurations of these novel polyketides, whereas enantiomers were separated from racemic mixtures when possible. Furthermore, based on careful structural analysis, a rational light-dependent biogenetic route was proposed for isolates 1-4. Photochemical reactions and rearrangements are determinant in the generation of complexity in this compound series, and we demonstrate through this work that there are still important discoveries to make with $\gamma$-pyrone polypropionates.

Finally, strikingly complex biomimetic semisynthetic transformations were performed to afford novel compound 1 from natural precursor $\mathbf{5}$, which not only nicely supported our proposed biosynthetic pathway, but also led to the production of side product 11. Reasoning that this compound could also be formed in vivo, the successful search of $\mathbf{1 1}$ in the crude extract of the mollusk by comparative LC-MS/MS gave a stunning insight on the role of biomimetic synthetic strategies to discover novel natural products.

\section{Acknowledgements}

This research work was financially supported by the National Natural Science Foundation of China (NSFC) (Nos. 81991521, 41676073, 81520108028, 21672230), the NSFC/CNRS joint project (No. 81811530284), the National Key Research and Development Program of China (No. 2018YFC0310903), the Drug Innovation Major Project (No. 2018ZX09711-001-001-009), and the SKLDR/ SIMM Project (No. SIMM1903ZZ-04). X.-W. Li is also thankful for the support of "Youth Innovation Promotion Association" (No. 2016258) from Chinese Academy of Sciences and SA-SIBS Scholarship Program. We thank Miss Christiane Waldrich for the taxonomic identification of the mollusk material. 
Keywords: Marine Natural Products - Polyketides • Sacoglossan mollusk • Biosynthetic rearrangements • Biomimetic Synthesis

[1] a) Puglisi, M. P.; Sneed, J. M.; Ritson-Williams, R.; Young, R. Nat. Prod. Rep. 2019, 36, 410-429; b) Bornancin, L.; Bonnard, I.; Mills, S. C.; Banaigs B. Nat. Prod. Rep. 2017, 34, 644-676; c) Dean, L. J.; Prinsep, M. R. Nat. Prod. Rep. 2017, 34, 1359-1390.

[2] a) Ireland, C.; Scheuer, P. J. Science. 1979, 205, 922-923; b) Trench, R. K. Nature. 1969, 222, 1071-1072.

[3] a) Davies-Coleman, M. T.; Garson, M. J. Nat. Prod. Rep. 1998, 15 477-493; b) Powell, K.J.; Richens, J. L.; Bramble,J. P.; Han, L.-C.; Sharma, P.; O'Shea, P.; Moses, J. E. Tetrahedron. 2017, 74, 1191-1198 c) Gavagnin, M.; Spinella, A.; Castelluccio, F.; Arnaldo, M.; Cimino, G. J. Nat. Prod. 1994, 57, 298-304.

[4] Marzo, V. Di.; Vardaro, R. R.; Petrocellis, L. De.; Villani, G.; Minei, R.; Cimino, G. Experientia. 1991, 47, 1221-1227.

[5] a) Cueto, M.; D'Croz, L.; Maté, J. L.; San-Martín, A.; Darias, J. Org. Lett. 2005, 7, 415-418; b) Zuidema, D. R.; Miller, A. K.; Trauner, D.; Jones, P. B. Org. Lett. 2005, 7, 4959-4962; c) Zuidema, D. R.; Jones, P. B. J. Nat. Prod. 2005, 68, 481-486.

[6] Lin, Z.; Torres, J. P.; Ammon, M. A.; Marett, L.; Teichert, R. W.; Reilly, C. A.; Kwan, J. C.; Hughen, R. W.; Flores, M.; Tianero, M. D.; Peraud, O.; Cox, J. E.; Light, A. R.; Villaraza, A. J.; Haygood, M. G.; Concepcion, G. P.; Olivera, B. M.; Schmidt, E. W. A Bacterial Source for Mollusk Pyrone Polyketides. Chem. Biol. 2013, 20, 73-81.

[7] Cutignano, A.; Villani, G.; Fontana, A. One Metabolite, Two Pathways: Convergence of Polypropionate Biosynthesis in Fungi and Marine Molluscs. Org. Lett. 2012, 14, 992-995.

[8] Torres, J. P. Lin, Z.Winter, J. M. Krug, P. J. Schmidt, E W. Animal Biosynthesis of Complex Polyketides in a Photosynthetic Partnership. BioRxiv, doi: https://doi.org/10.1101/764225.

[9] a) Cutignano, A.; Cimino, G.; Villani, G.; Fontana, A. ChemBioChem. 2009, 10, 315-322; b) Carbone, M.; Ciavatta, M. L.; Wang, J. R.; Cirillo, I.; Mathieu, V.; Kiss, R.; Mollo, E.; Guo, Y.-W.; Gavagnin, M. J. Nat. Prod. 2013, 76, 2065-2073.

[10] a) Miller, A. K.; Trauner, D. Angew. Chem. Int. Ed. 2005, 44, 4602-4606; b) Eade, S. J. Walter, M. W. Byrne, C. Odell, B. Rodriguez, R. Baldwin, J. E.; Adlington, R. M.; Moses, J. E. J. Org. Chem. 2008, 73, 4830-4839; c) Sharma, P.; Griffiths, N.; Moses, J. E. Org. Lett. 2008, 10, 4025-402; d) Sharma, P.; Lygo, B.; Lewis, W.; Moses, J. E. J. Am. Chem. Soc. 2009, 131, 5966-5972.

[11] a) Fu, X.; Hong, E. P.; Schmitz, F. J. Tetrahedron. 2000, 56, 8989-8993; b) Manzo, E.; Ciavatta, M. L.; Gavagnin, M.; Mollo, E.; Wahidulla, S.; Cimino, G. Tetrahedron. Lett. 2005, 46, 465-468.

[12] a) Carbone, M.; Li, Y.; Irace, C.; Mollo, E.; Castelluccio, F.; Di Pascale, A.; Cimino, G.; Santamaria, R.; Guo, Y.-W.; Gavagnin, M. Org. Lett. 2011, 13, 2516-2519; b) Wu, Q.; Chen, W.-T.; Li, S.-W.; Ye, J.-Y.; Huan, X.-J.; Gavagnin, M.; Yao, L.-G.; Wang, H.; Miao, Z.-H.; Li, X.-W.; Guo, Y.-W. Mar. Drugs. 2019, 17, 56-67; c) Huang, R.-Y.; Chen, W.-T.; Kurtán, T.; Mándi, A.; Ding, J.; Li, J.; Li, X.-W.; Guo, Y.-W. Future Med. Chem. 2016, 8, 17-27; d) Carbone, M.; Gavagnin, M.; Mattia, C.A.; Lotti, C.; Castelluccio, F.; Pagano, B.; Mollo, E.; Guo, Y.-W.; Cimino, G. Tetrahedron, 2009, 65, 4404-4409; e) Zhou, Z.-F.; Li, X.-L.; Yao, L.-G.; Li, J.; Gavagnin, M.; Guo, Y.-W. Bioorg. Med. Chem. Lett. 2018, 28, 1093-1096; f) Li, S.-W.; Cui, W.-X.; Huan, X.-J.; Gavagnin, M.; Mollo, E.; Miao, Z.-H.; Yao, L.-G.; Li, X.-W.; Guo, Y.-W. Nat. Prod. Res. 2019, doi.org/10.1080/14786419.2019.1569010.

[13] Gavagnin, M.; Mollo, E.; Cimino, G. Ortea, J. Tetrahedron. Lett. 1996, 37, 4259-4262.

[14] Gavagnin, M.; Mollo, E.; Cimino, G. Rev. Bras. Farmacog. 2015, 25 , 588-591.

[15] Brown, P. D.; Lawrence, A. L. Nat. Prod. Rep. 2017, 34, 1193-1202.

[16] a) Liu, M.; Sun, W.; Shen, L.; He, Y.; Liu, J.; Wang, J.; Hu, Z.; Zhang, Y. Angew. Chem. Int. Ed. 2019, 58, 12091-12095; b) Helgaker, T.; Jaszuński, M.; Ruud, K. Chem. Rev. 1999, 99, 293-352; c) Gaussian 09, Revision A.02, Frisch, M. J.; Trucks, G. W.; Schlegel, H. B.; Scuseria, G. E. Robb, M. A.; Cheeseman, J. R. Scalmani, G.; Barone, V.; Petersson, G. A.; Nakatsuji, H.; Li, X.; Caricato, M.; Marenich, A.; Bloino, J.; Janesko, B. G.; Gomperts, R.; Mennucci, B.; Hratchian, H. P.; Ortiz, J. V.; Izmaylov, A. F.; Sonnenberg, J. L.; Williams-Young, D.; Ding, F.; Lipparini, F.; Egidi, F.; Goings, J.; Peng, B.; Petrone, A.; Henderson, T.; Ranasinghe, D.; Zakrzewski, V. G.; Gao, J.; Rega, N.; Zheng, G.; Liang, W.; Hada, M.; Ehara, M.; Toyota, K.; Fukuda, R.; Hasegawa, J.; Ishida, M.; Nakajima, T.; Honda, Y.; Kitao, O.; Nakai, H.; Vreven, T.; Throssell, K.; Montgomery, J. A.; Peralta, J. E. Jr.; Ogliaro, F.; Bearpark, M.; Heyd, J. J.; Brothers, E.; Kudin, K. N.; Staroverov, V. N.; Keith, T.; Kobayashi, R.; Normand, J.; Raghavachari, K.; Rendell, A.; Burant, J. C.; Iyengar, S. S.; Tomasi, J.; Cossi, M.; Millam, J. M.; Klene, M.; Adamo, C.; Cammi, R.; Ochterski, J. W.; Martin, R. L.; Morokuma, K.; Farkas, O.; Foresman, J. B.; Fox, D. J. Gaussian, Inc., Wallingford CT, 2016.

[17] Li, W.-S.; Hu, H.-B.; Huang, Z.-H.; Yan, R.-J.; Tian, L.-W.; Wu, J. Org. Lett. 2019, 21, 7919-7922.

[18] a) Müller, M.; Kusebauch, B.; Liang, G.; Beaudry, C. M.; Trauner, D.; Hertweck, C. Angew. Chem. Int. Ed. 2006, 45, 7835-7838; b) Hertweck, C. Angew. Chem. Int. Ed. 2009, 48, 4688-4716.
[19] a) Pescitelli, G.; Di Bari, L.; Berova, N. Chem. Soc. Rev. 2011, 40, 4603-4625; b) Li, X.-C.; Ferreira, D.; Ding, Y. Curr. Org. Chem. 2010, 14 1678-1697; c) Bringmann, G.; Bruhn, T.; Maksimenka, K.; Hemberger, Y. Eur. J. Org. Chem. 2009, 17, 2717-2727.

[20] Suzuki, M.; Ohtake, H.; Kameya, Y.; Hamanaka, N.; Noyori, R. J. Org. Chem. 1989. 54, 5292-5302.

[21] Burghart-Stoll, H..; Brückner, R. Org. Lett. 2011. 13, 2730-2733.

[22] a) Cheng, H. H.; Wang, H. K.; Ito, J.; Bastow, K. F.; Tachibana, Y.; Nakanishi, Y.; Xu, Z.; Luo, T. Y.; Lee, K. H. J. Nat. Prod. 2001, 7, 915-919; b) Hynninen, P.H.; Hyvärinen, K. J. Org. Chem. 2002, 67, 4055-4061.

[23] Li, D.; Schröder, K.; Bitterlich, B.; Tse, M. K.; Beller, M. Iron-catalyzed Hydroxylation of $\beta$-Ketoesters with Hydrogen Peroxide as Oxidant Tetrahedron. Lett. 2008, 41, 5976-5979.

[24] Yang, J.-Y.; Sanchez, L.M.; Rath, C.M.; Liu, X.-T.; Boudreau, P.D.; Bruns, N.; Glukhov, E.; Wodtke, A.; de Felicio, R.; Fenner, A.; Wang, W.-R.; Linington, R.G.; Zhang, L.-X.; Debonsi, H.M.; Gerwick, W.H.; Dorrestein, P.C. Molecular Networking as a Dereplication Strategy. J. Nat. Prod. 2013, 76, 1686-1699.

[25] Bonneau, N.; Chen, G.; Lachkar, D.; Boufridi, A.; Gallard, J.-F.; Retailleau, P.; Petek, S.; Debitus, C.; Evanno, L.; Beniddir, M. A Poupon, E. Chem. Eur. J. 2017, 23, 14454-14461. 


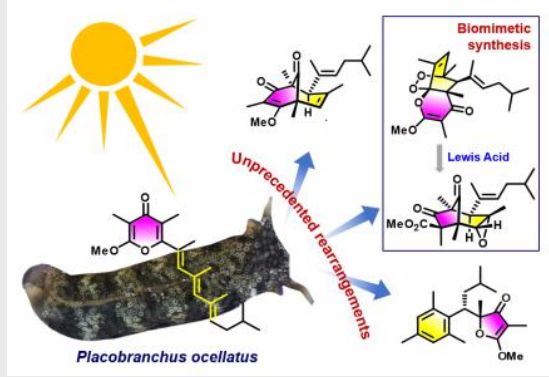

Qihao $W u^{1,2, \#, ~ S o n g-W e i ~ L i t, 3, \#, ~ H e n g ~}$ $\mathrm{Xu}^{1, \# \text {, Min Yang }}{ }^{1}$, Hong Wang ${ }^{2}$, Pei Hu${ }^{1}$, Cheng Luo ${ }^{1}$, Hao Zhang', Li-Gong Yao', Bastien Nay ${ }^{*, 4}$, Yue-Wei Guo $0^{*, 1,2,3}$ and Xu-Wen $L i^{*, 1}$

\section{Page No. - Page No.}

The Rise of Polypropionate Complexity in a South China Sea Photosynthetic Mollusk: Isolation and Biomimetic Synthesis Highlighting Unprecedented Rearrangements

A series racemic polypropionates with novel polycyclic skeletons were discovered and structurally elucidated from the South China Sea photosynthetic sacoglossan mollusk Placobranchus ocellatus. An important array of new and diversity-generating rearrangements is proposed to explain the biosynthesis of these unusual compounds. Furthermore, the successful biomimetic semisynthesis of ocellatusone A (1) confirmed the proposed rearrangement through an unprecedented acid promoted cascade reaction. Finally, the biomimetic synthesis provides a new strategy to explore the chemical space of Nature. 